\title{
Kinetics of liquid-phase shear exfoliation of graphite in synthetic oils
}

\author{
Zaman A A Alhilo ${ }^{1}$, Vladimir Pershin ${ }^{2}$, and Aleksey Osipov ${ }^{3}$ \\ ${ }^{1}$ Post-graduate student from the Republic of Iraq, Tambov State Technical University, 106 \\ Sovetskaya Street, 392000, Tambov, Russian Federation \\ ${ }^{2}$ Department of Technology and Methods of Nanoproducts Manufacturing, Tambov State Technical \\ University, 106 Sovetskaya Street, 392000, Tambov, Russian Federation \\ ${ }^{3}$ LLC “NanoTechCenter”, 51 Sovetskaya Street, 392000, Tambov, Russian Federation
}

\begin{abstract}
Lubricants modified with nanosized particles are of great interest to science and industry, since they have much better tribological characteristics compared to traditional lubricants. One of the most promising nanoparticles is graphene, which has an extremely low coefficient of friction, is very wear-resistant and environmentally friendly. Today, the main problem for the development of a new nano-lubricant is the creation of an environmentally friendly and cheap technology for the industrial production of graphene suspensions or graphene concentrates for the modification of traditional lubricants. The article describes the process of liquid-phase shear exfoliation of graphite in a rotary apparatus with moving blades, in synthetic oils. The kinetic dependences of the exfoliation process, i.e. the dependence of the concentration of graphene nanostructures in suspension over time at different values of the process parameters. It has been experimentally proved that using a stator-rotor mixer with moving blades, it is possible to obtain graphene nanostructure concentrations of at least $2 \mathrm{mg} / \mathrm{ml}$.
\end{abstract}

\section{Introduction}

Graphite has been used as an antifriction material for several centuries, but the production of graphene and graphene nanostructures (low-layer graphene and multilayer graphene) has greatly increased the interest of scientists and engineers in this material [1,2]. It has been experimentally established that the addition of graphene nanostructures to lubricants reduces not only the coefficient friction and wear, but also at times increases the ultimate load on friction pairs. The experimental results show that the addition of $0.4 \mathrm{wt} . \%$ graphene nanostructures to lithium greases gives good antifriction properties and wear resistance [3, 4]. Processing graphite lubricant in a ball planetary mill and converting a portion of graphite into low-layer and multi-layer graphene reduced the friction coefficient by $2.2-2.5$ times [6]. Improving the tribological characteristics of lubricants by adding low-layer and multi-layer graphene is one of the most promising ways to reduce friction and wear in various machines and mechanisms. The results of our studies confirm the promise of this

*Correspondingauthor:pershin home@mail.ru 
area. The main obstacle to the transition from laboratory miserable volumes to largetonnage industrial technologies is the lack of environmentally friendly and cheap methods for producing low-layer and multi-layer graphene, which can be used to modify lubricants. An analysis of the use of nanomaterials to improve the operational characteristics of lubricants showed that one of the most promising is liquid-phase shear exfoliation of graphite. One of the first full-scale studies was conducted to obtain aqueous suspensions of graphene nanostructures using shear exfoliation in a stator-rotor mixer [6]. The results of these studies quickly found practical application in the modification of concrete with graphene nanostructures [7]. Our group improved the design of the stator-rotor of the mixer and began to use moving blades, which fundamentally changed the mechanism of shear exfoliation. If in the works $[6,7]$ the exfoliation of graphite particles was carried out in a very thin (less than $0.1 \mathrm{~mm}$ ) high-speed fluid flow, in our design shear effects on particles in graphite are transmitted directly from the blade, which glides along the inner surface of the stator. To move to the industrial scale of production of suspensions, which contain lowlayer and multi-layer graphene, it is necessary to know the kinetics of the process, i.e. how the concentration of graphene nanostructures changes over time if the geometric and operational parameters of the process change. It is these problems that are investigated in this article.

\section{Experiment}

We conducted experimental studies on the installation, which is shown in figure 1 . The main unit is a rotary apparatus with movable blades, similar to the one that we used earlier [8].

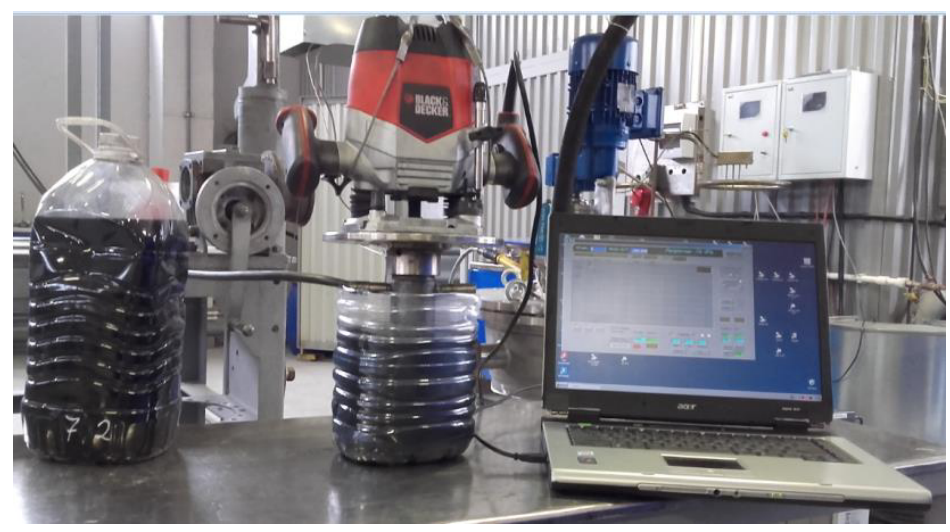

Fig. 1. Experimental setup for exfoliation of graphite in oil.

In contrast to this design, this stator was equipped with upper and lower covers. In addition, there were only two holes in the stator. One in the upper part of the stator and through this hole from the tank, which was located above the apparatus, the suspension was discharged into the apparatus by a pump with a fixed flow rate. The second hole is located in the lower part of the stator and through this hole the suspension exits the apparatus into a container.

After all the suspension from the upper tank passed through the rotor apparatus, the rotor rotation drive was turned off and the suspension treatment cycle ended. The suspension was pumped from the lower tank to the upper tank and the recycle cycle was repeated. This scheme, unlike the one used in the works [6,7], guaranteed the processing of the entire suspension in one cycle. As a rotor rotation drive, we used a Black \& Decker milling machine with a power of 1200 watts and a rotation speed of up to $27,000 \mathrm{rpm}$. A 
control unit for rotation speed and fixing of power consumption was specially designed and manufactured. This made it possible to control the process and record all process parameters on a personal computer.

As source materials we used: industrial oil I20A; organosilicon liquid; polyaliphine oil; crystalline graphite powder GSM-2. During the experiments, the following was changed: the concentration of graphite in the initial suspension from 1 to 5 weight percent; rotor speed from 6000 to $20,000 \mathrm{rpm}$; suspension flow rate, i.e. the volume that passed through the rotary apparatus per unit time from $31 / \mathrm{min}$ to $151 / \mathrm{m}$.

After every 30 treatment cycles, samples were taken from the suspension and the concentration of graphene nanostructures in the suspension were determined. In the first series of experiments, a mixture of oil and graphite with different concentrations was used as the initial suspension. In the second series of experiments, the initial mixture with a graphite concentration of $10 \%$ was processed in a rod drum mill for 1 to 2 hours, then pure oil was added to the mixture so that the concentration of graphite and the resulting graphene nanostructures was from 1 to $5 \%$ and then the suspension was started to be processed on a rotary apparatus. Thus, in the second series of experiments, graphene nanostructures were already in the initial suspension, and graphite particles were mechanically activated.

\section{Results and discussion}

Figure 2 shows the characteristic dependence of the change in the concentration of graphene structures in suspension on the number of treatment cycles. It should be especially noted that since the suspension was passed through a rotary apparatus, the number of treatment cycles could be clearly fixed. The graph shows that after 60-90 cycles, the concentration does not increase. Given this fact, in further studies, the concentration of graphite in the initial suspension was increased and the yy was processed from 20 to 30 cycles.

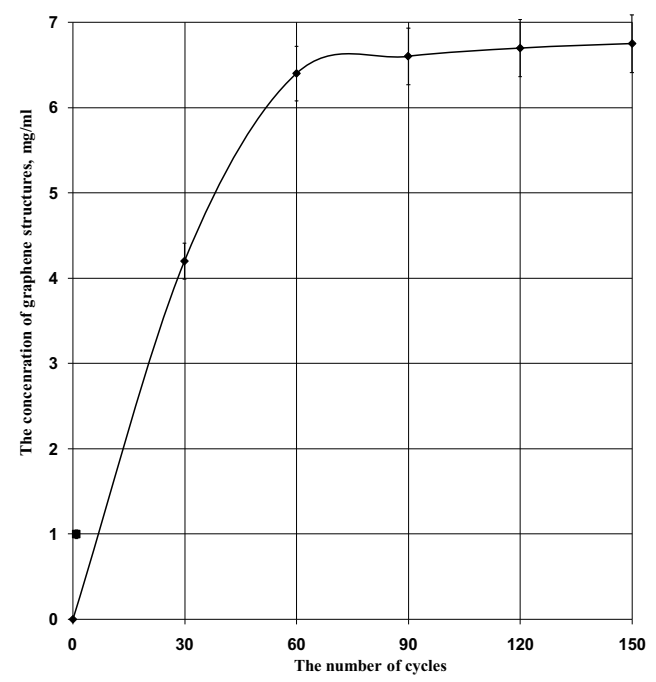

Fig. 2. The dependence of the concentration of graphene structures in suspension on the number of cycles

Figure 3 shows the dependence of the change in the optical density coefficient on the number of treatment cycles for the initial suspension (curve 1) and the suspension pretreated in a core drum mill. On the graphs, you can see that curve 2 is slightly steeper 
than curve 1. After pre-treatment in a rotary bar drum mill, the maximum concentration is reached faster and is 1.5 times higher than for untreated suspension (curve 1).

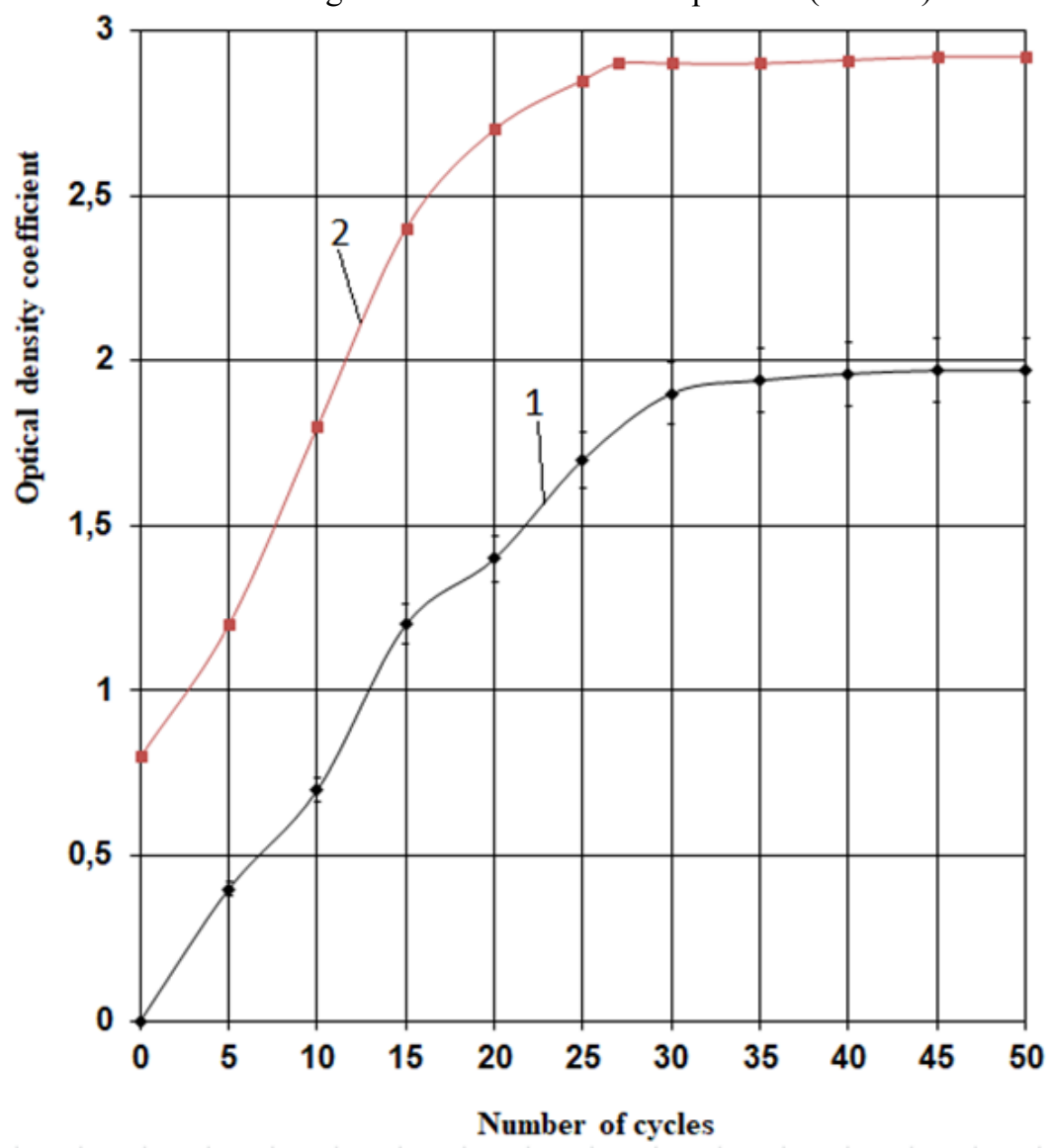

Fig. 3. Dependence of the change in the optical density coefficient on the number of treatment cycles

Figure 4 shows the characteristic dependence of the change in the optical coefficient on the number of cycles, with periodic addition of pure oil to the suspension. On the graphs, you can see that when processing a mechanically activated suspension, curve 2 is steeper than curve 1 and faster reaches the maximum optical coefficient, and therefore the maximum concentration of graphene nanostructures in the suspension. It is very important to note that despite the fact that the optical coefficient at 20 and 40 processing cycles is almost the same, the liquid volume is 2 times larger and this means that the mass of graphene particles is also 2 times larger. Of course, it must be borne in mind that after adding pure oil not only the volume has increased, but also the time during which one processing cycle is carried out. However, if the volume increased by 2 times, then the time of one cycle increased by a maximum of 1.5 times, because after adding oil, the viscosity of the suspension decreased and, consequently, the volumetric productivity of the rotor apparatus increased. However, this is a new problem that requires additional research. In this article, we did not set ourselves such a task. At the moment, we can only say that the productivity of the rotary apparatus with the periodic addition of pure oil, in terms of dry graphene nanostructures, increased by $33 \%$. Indeed, if we received $10 \mathrm{~g}$ in 10 minutes, and began to receive 20 grams in 15 minutes, then the increase in productivity by $33 \%$. 


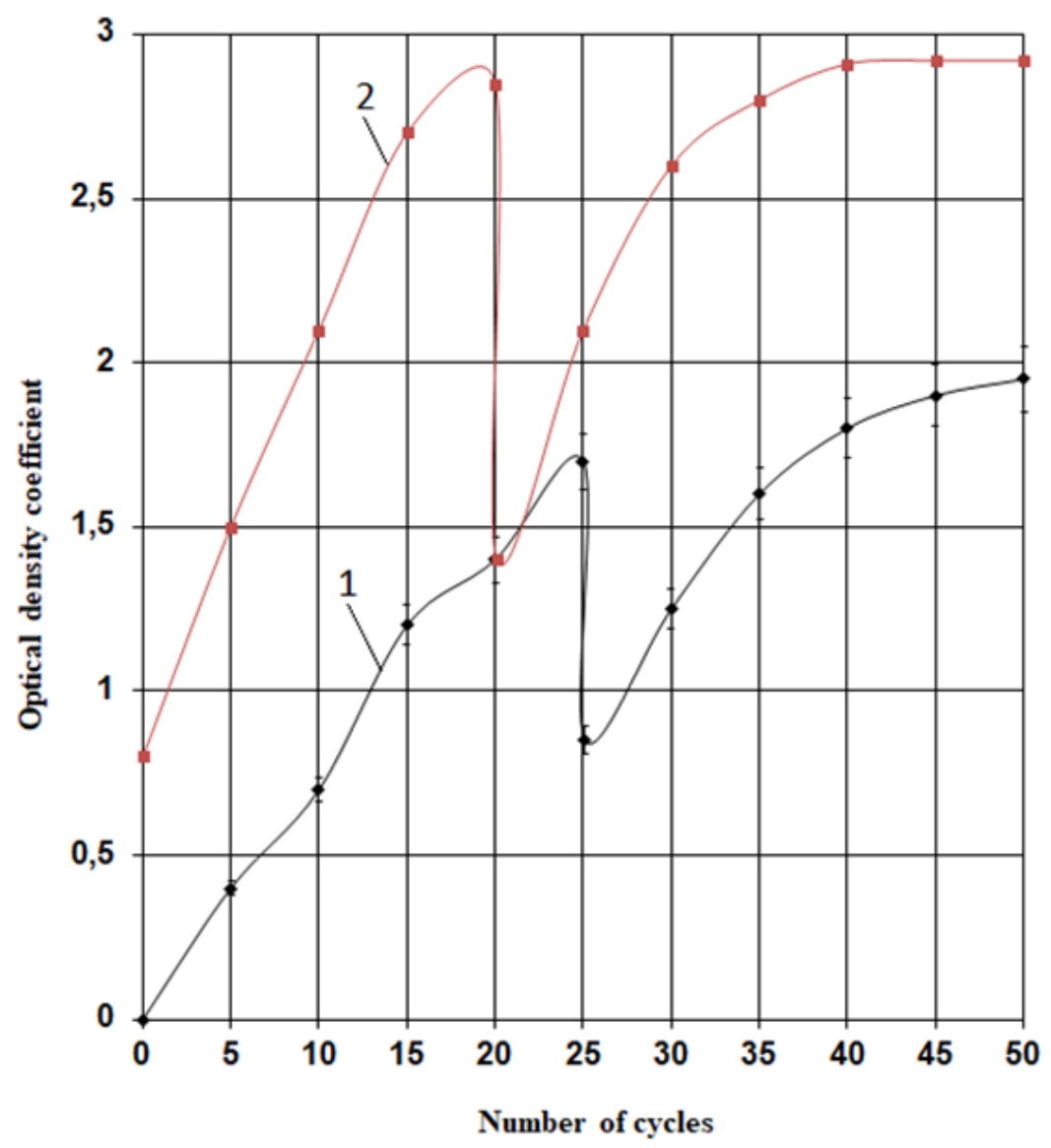

Fig. 4. Dependence of the change in the optical coefficient on the number of cycles, with periodic addition of pure oil to the suspension

\section{Conclusion}

As a result of experimental studies, it has been established that the concentration of graphene structures in the finished suspension is directly proportional to: the number of processing cycles; rotor speed; the concentration of graphite in the original suspension. In addition, it was found that to increase the efficiency of the exfoliation process, the fraction of graphite that could be converted into graphene structures can be achieved by periodically reducing the concentration of graphene structures in the suspension being processed, by adding pure liquid to this suspension. The technology for producing graphene structures directly in oil by shear exfoliation of graphite has good prospects for industrial implementation.

The reported study was funded by RFBR, project number 19-38-90159.

\section{References}

1. M.A.M. Souza, L.C. Pardini, Materia, 21(3), 706-713 (2016)

2. D. Berman, S.A. Deshmukh, Adv. Funct. Mater., 24(42), 6640-6646 (2014) 
3. A.A. Gomaa, M.I. Khashaba, J. Multidiscip. Eng. Sci. Technol., 3(8), 5459-5465 (2016)

4. V.F. Pershin, K.A. Ovchinnikov, A.A. Alsilo, R.A. Stolyarov, N.R. Memetov, Nanotechnol. Russ. 13(5-6), 344-348 (2018)

5. D.A.Y. Al-Saadi, V.F. Pershin, B.N. Salimov, S.A. Montaev, J. Frict. Wear 38(5), 355358 (2017)

6. K.R. Paton, E. Varrla, C. Backes, R.J. Smith, U. Khan, A. O’Neill, C. Boland, M. Lotya, O.M. Istrate, P. King, T. Higgins, S. Barwich, P. May, P. Puczkarski, I. Ahmed, M. Moebius, H. Pettersson, E. Long, J. Coelho, S.E. O’Brien, E.K. McGuire, B.M. Sanchez, G.S. Duesberg, N. McEvoy, T.J. Pennycook, C. Downing, A. Crossley, V. Nicolosi, J.N. Coleman, Nat. mater. 13(6), 3944 (2014)

7. D. Dimov, I. Amit, O. Gorrie, M.D. Barnes, N.J. Townsend, A.I. Neves, F. Withers, S. Russo, M.F. Craciun, Adv. Funct. Mater. 28, 1705183 (2018)

8. K.A. Al-Shiblawi, A.A. Pasko, V.F. Pershin, Transactions TSTU, 24(4), 717-726 (2018) 